\title{
Caracterização de espécies diploides de Lotus em resposta à toxidez por alumínio $^{1}$
}

\section{Armando Martins dos Santos ${ }^{2}$, Miguel Dall'Agnol' ${ }^{2}$, Aline Janke ${ }^{2}$, Carlos Alberto Bissani ${ }^{3}$, Luciana Carvalho dos Santos ${ }^{2}$, Marcos Laux de Leão ${ }^{2}$}

\author{
1 Trabalho financiado pelo projeto Lotassa. \\ 2 Departamento de Plantas Forrageiras e Agrometeorologia, Faculdade de Agronomia da Universidade Federal do Rio Grande do Sul. \\ Av. Bento Gonçalves, 7712 - Caixa Postal 15100 - 91540-000. \\ ${ }^{3}$ Departamento de Solos, Faculdade de Agronomia da Universidade Federal do Rio Grande do Sul. Av. Bento Gonçalves, 7712 - \\ Caixa Postal 15100 - 91540-000.
}

RESUMO - Objetivou-se com este trabalho caracterizar espécies diploides, inclusive a espécie modelo Lotus japonicus, e linhas endogâmicas recombinantes do gênero Lotus, quanto à tolerância ao alumínio (Al) tóxico utilizando-se solo ácido e solução nutritiva. Os experimentos foram conduzidos em casa-de-vegetação, sendo testadas três espécies diploides (L. japonicus MG-20 e GIFU, L. filicaulis e L. burtii) e 180 linhas endogâmicas recombinantes. Nos experimentos com espécies diploides, utilizou-se a alfafa como testemunha sensível e, nos experimentos com linhas endogâmicas recombinantes, utilizou-se a espécie modelo GIFU. Nos experimentos em solo, foram avaliadas características morfológicas da parte aérea e da raiz e, nos experimentos em solução nutritiva, apenas o comprimento e crescimento radicular. As espécies modelo MG-20 e GIFU foram, em geral, as mais produtivas. Os resultados em solução nutritiva seguiram padrão de resposta semelhante ao observado nas avaliações em solo ácido, sendo a espécie MG-20 superior às demais em todas as concentrações de alumínio testadas. Das 180 linhas endogâmicas recombinantes testadas, 24 foram superiores e 39 inferiores à espécie GIFU. A grande diversidade observada nas espécies modelo e nas linhas endogâmicas recombinantes pode auxiliar na futura seleção de genótipos cultivados (tetraploides), uma vez que essas espécies possuem um grupo de marcadores moleculares desenvolvidos que podem ser utilizados na identificação de regiões responsáveis pela maior ou menor tolerância à toxidez por alumínio.

Palavras-chave: alumínio tóxico, espécie modelo, linha endogâmica recombinante

\section{Characterization of diploid species of Lotus in response to aluminum toxicity}

\begin{abstract}
The objective of this work was to characterize diploid species, including Lotus japonicus model species and recombinant inbred lines of the Lotus genus for resistance to aluminum (Al) toxicity by using acid soil and nutrient solution. The experiments were conducted in greenhouse, being tested three diploid species (L. japonicus MG-20 and GIFU, L. filicaulis and L. burtii), and 180 recombinant inbred lines. In the experiments with diploid species, alfalfa was used as a check, and in the experiments with recombinant inbreed lines, GIFU model species was used. In the soil experiments, the morphological characteristics of the aerial part and the root were evaluated, and in the nutrient solution experiment, only the root length and growth were evaluated. MG-20 and GIF model species were the most productive in general. The results in nutrient solution followed the response pattern similar to the one observed in acid soil evaluations. The MG-20 genotype was superior to the others in all $\mathrm{Al}$ concentrations tested. Of the 180 recombinant inbred lines tested, 24 were superior and 39 inferior to the GIFU species. The great diversity observed in the model species and in the recombinant inbred lines can help in future selection of cultivated genotypes (tetraploids) inasmuch as they have a group of developed molecular markers which can be used at identification of regions responsible for higher or lower tolerance to aluminum toxicity.
\end{abstract}

Key Words: model specie, recombinant inbred line, toxic aluminum

\section{Introdução}

A crescente pressão imposta pela exploração intensiva das grandes monoculturas tem levado as áreas de pastagem para regiões marginais, que geralmente apresentam solos com baixa fertilidade, alta acidez decorrente da toxidez por alumínio. Somente na América tropical, cerca de 850 milhões de hectares apresentam esse tipo de problema 
(Rao et al., 1993). A seleção e o melhoramento visando tolerância a estresses abióticos em leguminosas forrageiras poderiam reduzir esses efeitos, aumentando a produção e qualidade de forragem também em áreas que apresentem toxidez por alumíno. No entanto, geralmente esse procedimento é limitado pelo modo de reprodução destas espécies (alogamia) e pela complexidade das respostas fisiológicas e metabólicas aos estresses. Acrescenta-se a isso a limitada quantidade de informação disponível a respeito dessas espécies.

Como os genomas de algumas espécies forrageiras são altamente relacionados ao genoma de Lotus japonicus, uma espécie diploide modelo que possui um mapa genético bem desenvolvido (Gueta-Dahan et al., 1997) e caracterização e identificação de indivíduos diploides contrastantes quanto à tolerância ao alumínio poderia facilitar a identificação das regiões genômicas responsáveis por essa característica, pelo uso de marcadores desenvolvidos para essa espécie modelo.

No caso da acidez do solo, a caracterização em vasos contendo solo ácido serviria para embasar futuras seleções de materiais cultivados, mais convenientes às necessidades locais, entretanto, segundo Samac \& Tesfaye (2003), essa metodologia se torna muito trabalhosa e demorada devido à dificuldade na coleta e processamento de grandes volumes de solo, do tempo para correção do solo e da dificuldade de coletar solo representativo do horizonte A. O uso ou adaptação de técnicas com solução nutritiva que avaliem as plantas em seu estádio inicial permite caracterizar mais genótipos, de maneira mais simples, em um curto período de tempo, evitando os inconvenientes acima citados (Menosso, 2000).

Objetivou-se com este trabalho avaliar o efeito da correção da acidez do solo no desenvolvimento de quatro genótipos de três espécies diplóides do gênero Lotus; estudar a eficiência de um método rápido utilizando plântulas em solução nutritiva para verificar a tolerância ao alumínio tóxico, comparando os resultados obtidos com os experimentos realizados em solo ácido; e caracterizar em solução nutritiva a tolerância ao alumínio de 180 linhas endogâmicas recombinantes (LER) originadas a partir do cruzamento de L. japonicus com L. japonicus, L. burtii e L. filicaulis.

\section{Material e Métodos}

Os experimentos foram conduzidos em casa-devegetação entre junho de 2005 e outubro de 2008. Foram realizados oito experimentos: um para caracterização das espécies diploides em solo ácido com diferentes saturações de alumínio; um para a caracterização precoce dessas mesmas espécies em solução nutritiva com diferentes concentrações de alumínio e seis experimentos para o teste das linhas endogâmicas recombinantes na concentração $50 \mu \mathrm{mol} / \mathrm{L}(\mu \mathrm{M})$ de alumínio. Essa concentração de alumínio foi baseada em resultados coletados em experimentos preliminares.

Foram testados quatro genótipos diploides de três espécies do gênero Lotus (L. japonicus GIFU e MG-20, L. burtii e L. filicaulis) e 180 linhas endogâmicas recombinantes (63 provenientes de L. japonicus (MG1 até MG128, além dos genótipos KOREA e CHURUI), 87 provenientes do cruzamento entre $L$. burtii $\times$ L. japonicus GIFU (GLB1 até GLB198) e 30 provenientes do cruzamento entre L. japonicus $\times$ L. filicaulis (NS1 até NS180). Adicionalmente, utilizaram-se a alfafa crioula, espécie sensível ao alumínio, como testemunha no experimento com espécies diplóides (solo ácido e solução nutritiva) e o ecótipo GIFU para os experimentos com as linhas endogâmicas recombinantes.

Para a caracterização dos genótipos em solo ácido, utilizou-se solo coletado em junho de 2005 no município de André da Rocha, em área de beira de estrada, vegetada por campo nativo, que apresenta ocorrência de Latossolo Vermelho Distroférrico típico (comissão de química e fertilidade do solo - RS/SC, 2004). O solo foi seco ao ar, destorroado, peneirado e acondicionado em potes plásticos com capacidade para $1,5 \mathrm{~kg}$. Foi realizada análise físicoquímica deste solo (Tabela 1), cujos valores de pH, CTC pH 7,0, saturação por bases e saturação por alumínio foram interpretados como muito baixo, médio, muito baixo e alto, respectivamente (comissão de química e fertilidade do solo - RS/SC, 2004).

Realizou-se em cada pote isoladamente das cinco repetições, a aplicação de seis níveis de calagem, em doses equivalentes a $0 ; 12,5 ; 25 ; 50 ; 50$ e $100 \%$ da dose indicada

Tabela 1 - Caracterização físico-química do solo coletado no município de André da Rocha, Rio Grande do Sul, em junho de 2005

\begin{tabular}{|c|c|c|c|c|c|c|}
\hline \multirow{2}{*}{$\begin{array}{c}\text { Argila } \\
\%\end{array}$} & \multirow{2}{*}{$\begin{array}{c}\mathrm{pH} \\
\mathrm{H}_{2} 0\end{array}$} & \multirow{2}{*}{$\begin{array}{l}\text { Índice } \\
\text { SMP }\end{array}$} & $\mathrm{P}$ & $\mathrm{K}$ & Ca troc & $\mathrm{Mg}$ troc \\
\hline & & & \multicolumn{2}{|c|}{$\mathrm{mg} / \mathrm{dm} 3$} & \multicolumn{2}{|c|}{$\mathrm{cmols} / \mathrm{dm}^{3}$} \\
\hline$>60$ & 4,8 & 5,0 & 1,5 & 32 & 0,5 & 0,3 \\
\hline Al troc & $\mathrm{H}+\mathrm{Al}$ & CTC efetiva & CTC pH 7,0 & Sat $\mathrm{Al}$ & Sat bases & MO \\
\hline & -- & $\mathrm{Im}^{3}--$ & & & $\%-$ & -- \\
\hline 4,6 & 13,3 & 5,5 & 14,2 & 82,5 & 7,1 & 2,2 \\
\hline
\end{tabular}


pelo índice SMP para se obter $\mathrm{pH}$ 6,0, com base nas recomendações da Comissão de Química e Fertilidade do Solo - Rio Grande do Sul/Santa Catarina (2004). O valor 100\% SMP para este solo foi de 9,9 t/ha. Para a correção do solo, foi utilizada uma mistura de carbonato de cálcio e carbonato de magnésio (3:1). Com intuito de acelerar o processo de reação do carbonato no solo, foram realizados revolvimentos no solo incubado semanalmente.

Os seis níveis de correção implementados foram novamente avaliados após 80 dias de incubação, correspondendo aos valores de saturação por alumínio (Tabela 2).

Após o período de incubação, em 5/1/2006, foram semeadas aproximadamente 20 sementes/vaso de cada um das cinco populações tetraploides. Em cada vaso, foram aplicados o equivalente a $100 \mathrm{mg}$ de $\mathrm{N}, 100 \mathrm{mg}$ de $\mathrm{P}_{2} \mathrm{O}_{5} \mathrm{e}$ $100 \mathrm{mg}$ de $\mathrm{K}_{2} \mathrm{O}$, como ureia, superfosfato triplo e cloreto de potássio, na ocasião da semeadura.

Quando as plantas apresentavam em média 2 a 3 folhas trifolioladas, realizou-se um desbaste de homogeneização, deixando-se apenas 10 plantas por vaso.

Após 60 dias (3/3/2006) de crescimento, avaliaram-se a altura das plantas com auxílio de uma régua graduada em mm, o número de ramificações, pela contagem dos ramos, a área foliar, com auxílio de um planímetro ótico (Licor, modelo LI-6200), e a matéria seca da parte aérea, pela pesagem das hastes e folhas após a secagem por 72 horas em estufa de circulação de ar com temperatura de $65^{\circ} \mathrm{C}$.

O delineamento experimental utilizado foi inteiramente casualizado, com cinco repetições. Foram realizadas análises de variância em esquema fatorial $4 \times 6$ para as características avaliadas, utilizando-se o teste de Tukey a 5\% de probabilidade para a comparação, pelo pacote estatístico SAS (SAS Institute, 2001). Utilizou-se teste Tukey pelo fato de que objetivo principal do trabalho foi identificar a variabilidade dos germoplasmas em cada nível isoladamente e não o comportamento isolado de cada germoplasma nos diferentes níveis.

A seleção de plantas em solução nutritiva foi baseada na metodologia desenvolvida para soja, descrita por Menosso et al. (2000). As sementes foram colocadas sobre papel germinador em caixas tipo gerbox. As caixas foram mantidas em condições de casa-de-vegetação, visando garantir iluminação adequada, evitando assim o estiolamento. Foram utilizadas três repetições formadas por seis plântulas cada, utilizadas após sete dias, quando as radículas já apresentavam pelo menos $10 \mathrm{~mm}$. Foram utilizadas lâminas de poliestireno expandido (isopor ${ }^{\circledR}$ ) para a sustentação das plantas na solução, sendo estas conduzidas em bandejas plásticas com capacidade para $5 \mathrm{~L}$ de solução durante um período de 23 dias, totalizando 30 dias de experimento.

As soluções utilizadas foram baseadas em Wenzl et al. (2001), compostas por: $200 \mu \mathrm{mol} / \mathrm{L}(\mu \mathrm{M})$ de $\mathrm{Ca}^{2+}$ $\left(\mathrm{CaCl}_{2} \cdot 2 \mathrm{H}_{2} \mathrm{O}\right)$ e quatro doses de alumínio $(0,50,100$ ou $200 \mu \mathrm{M}$ de $\mathrm{Al}, \mathrm{AlCl}_{3} .7 \mathrm{H}_{2} \mathrm{O}$ ). Essas quatro soluções foram utilizadas desde o momento da semeadura. $\mathrm{O}$ pH das soluções foi ajustado para 4,2 e as soluções eram trocadas a cada três dias, visando evitar o acúmulo de exsudados e a alteração das concentrações de alumínio e $\mathrm{Ca}^{2+}$. O volume de água era completado quando necessário. A solução foi aerada com compressores com capacidade de 40 L/hora.

Foram avaliados o comprimento radicular inicial (aos sete dias após a germinação) e final (20 dias após a germinação), o crescimento radicular (comprimento final subtraído do comprimento inicial) e o número de ramificações radiculares após 20 dias de cultivo. A partir dos resultados, calcularam-se, de acordo com Wenzl et al. (2001), o crescimento radicular relativo (CRR) e a atividade de alumínio requerida para decrescer o crescimento radicular relativo para $50 \%\left(\left\{\mathrm{Al}^{+3}\right\}_{50}\right)$.

O crescimento radicular relativo (CRR) foi obtido pela equação $\mathrm{CRR}=100$. [(CR $\left.\left.\mathrm{Cl}_{\mathrm{l}}-\mathrm{CR} \partial\right) /\left(\mathrm{CR}_{0}-\mathrm{CR} \partial\right)\right]$, em que $\mathrm{CR}_{\mathrm{Al}}$; crescimento radicular na presença de determinada concentração de $\mathrm{Al}$; CRd: crescimento residual em níveis de alumínio suficientes para saturar o crescimento radicular e $\mathrm{CR}_{0}$ : crescimento médio das raízes na ausência de alumínio.

O delineamento experimental utilizado foi o inteiramente casualizado, com três repetições. Foram realizadas análises de variância para crescimento radicular, crescimento radicular relativo, número de ramificações radiculares, crescimento inicial e final. Utilizou-se o teste de Tukey a 5\%

Tabela 2 - pH do solo, saturação por alumínio, cálcio e magnésio trocáveis em solo ácido após incubação submetido a seis níveis de correção da acidez do solo

\begin{tabular}{lcccccc}
\hline Atributo & \multicolumn{5}{c}{ \% de correção da acidez do solo } \\
\cline { 2 - 6 } & 0 & 12,5 & 25 & 50 & 75 & 100 \\
\hline pH do solo & 4,31 & 4,57 & 4,65 & 4,80 & 5,10 & 6,15 \\
Saturação por Al (\%) & 57,9 & 34,4 & 32,5 & 22,2 & 0 & 14,1 \\
Ca trocável (cmols/dm ${ }^{3}$ ) & 0,5 & 1,6 & 3,3 & 5,7 & 7,8 & 10,4 \\
Mg trocável (cmols/dm $\left.{ }^{3}\right)$ & 0,3 & 0,8 & 1,8 & 2,6 & 3,1 & 4,2 \\
\hline
\end{tabular}


de probabilidade para comparação das médias, sendo as análises realizadas pelo pacote estatístico SAS (SAS Institute, 2001).

Para caracterização das linhas endogâmicas recombinantes em solução nutritiva, foi usada a mesma metodologia dos experimentos de caracterização para espécies diplóides em solução nutritiva descrito anteriormente. Foram utilizadas três repetições formadas por cinco plântulas cada, avaliadas 20 dias após a semeadura. Utilizou-se apenas a concentração $50 \mu \mathrm{M}$ de alumínio, que se mostrou mais adequada na avaliação das espécies diploides.

O delineamento experimental utilizado foi o inteiramente casualizado, com três repetições. Foi avaliado apenas o comprimento final da raiz após 20 dias de crescimento nas bandejas, realizando-se análise de variância seguida de teste de Dunnet a 10\% de probabilidade para a comparação de médias, utilizando-se o ecótipo GIFU como controle.

\section{Resultados e Discussão}

Para a matéria seca da parte aérea, observou-se diferença significativa entre genótipos, com interação significativa ( $\mathrm{P}<0,0001)$ entre os níveis de alumínio e as espécies avaliadas (Figura 1).

Comparando as espécies em mesma saturação por alumínio, observou-se que, em situações moderadas (14,1\% e 22,2\%), a espécie $L$. japonicus MG-20 destacou-se das demais. Na saturação de $14,1 \%$, destacaram-se ainda a alfafa e a espécie $L$. japonicus GIFU. Sabendo-se que a

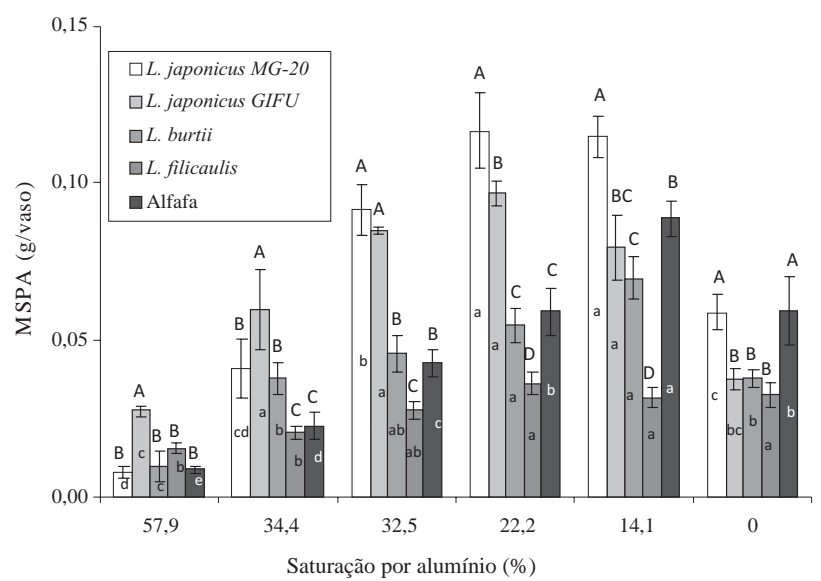

Letras minúsculas e maiúsculas indicam diferenças significativas pelo teste Tukey a 5\% de probabilidade entre os valores de saturação por alumínio de um mesmo germoplasma e entre os germoplasmas em determinado valor de saturação por alumínio, respectivamente.

Figura 1 - Matéria seca da parte aérea de quatro genótipos diploides de Lotus e de alfafa submetidos a seis níveis de saturação por alumínio. alfafa é reconhecidamente uma espécie sensível ao alumínio (Wheeler \& Dodd, 1995), a produção de matéria seca da parte aérea neste tratamento sugere que o efeito do alumínio neste nível de saturação foi baixo. A partir do tratamento $14,1 \%$ de saturação por alumínio, observou-se significativa redução na produção de MS da parte aérea da alfafa, com decréscimo de mais de $30 \%$ quando os valores da saturação aumentaram para $22,2 \%$. Esse comportamento também foi observado para a espécie L. burtii, que apresentou mais de $20 \%$ de redução na produção de MS da parte aérea. As demais espécies testadas (L. japonicus GIFU e MG-20 e L. filicaulis) não apresentaram redução na MS da parte aérea para nível 14,1\% de saturação por alumínio.

Níveis de 32,5\% de saturação por alumínio reduziram a MS da parte aérea em todas as espécies avaliadas. As espécies apresentaram de modo geral cerca de $20 \%$ da MS da parte aérea máxima observada, exceto em L. burtii, cujo valor de MS da parte aérea decresceu em 35\%. Na espécie controle (alfafa), a redução chegou a 50\% neste nível.

Em situações de elevada toxidez por alumínio (saturação de 34,4\%), a espécie $L$. japonicus GIFU foi superior às demais espécies, que apresentaram redução de mais de 50\% da MS da parte aérea em relação às maiores produções obtidas. Comportamento semelhante foi observado no maior nível de alumínio (saturação de 57,9\%). Apesar de a espécie L. japonicus GIFU ter sido superior quanto à produção de MS da parte aérea, ocorreu limitação severa da produção neste nível para todas as espécies. De maneira geral, os resultados da MS da parte aérea encontrados neste trabalho apresentaram resposta similar à encontrada em caracterização prévia (Santos et al., 2006).

Comparando-se a MS da parte aérea de cada espécie nos níveis de saturação por alumínio, observou-se que L. japonicus MG-20 e alfafa apresentaram as maiores variações entre os níveis de correção. Comparando as maiores e as menores produções destas espécies, observou-se redução de 93,4 e 90,2\%, respectivamente, na MS da parte aérea. As espécies L. burtii e L. japonicus GIFU apresentaram variação intermediária, com redução na ordem de 80,91 e 71,56\%, respectivamente. Já a espécie L. filicaulis foi a que apresentou menor variação na MS da parte aérea em relação à correção do solo, com apenas 57\% de redução. Esses resultados mostram que essa variável e a tolerância ao alumínio são inversamente proporcionais. Essa característica tem sido observada por autores como Foy et al. (1996) e Ma et al. (2001), que citaram a existência de um custo metabólico da tolerância, de modo que genótipos mais tolerantes desenvolveram mecanismos diferenciados, que, na ausência do estresse, deslocam recursos que poderiam ser alocados para crescimento. Como as plantas 
geralmente são destinadas a áreas parcialmente corrigidas, com moderada saturação de alumínio, espécies com elevado decréscimo na produção, assim como espécies que mantenham baixa produção independente da saturação por alumínio, não são os genótipos mais indicados. Deve-se buscar equilíbrio entre a produção e saturação por alumínio. Para este estudo, ambos os ecótipos da espécie modelo L. japonicus (MG-20 e GIFU) foram os mais produtivos nas condições de moderada saturação, com destaque para a espécie $L$. japonicus GIFU, que também foi superior em situações elevadas de toxidez por alumínio.

Em ausência de saturação por alumínio, observou-se redução na MS da parte aérea em todas as espécies, porém essa redução foi menos acentuada em alfafa e L . japonicus MG-20. Entre as explicações para o efeito depressivo desse nível de calagem, poderia estar alguma limitação nutricional decorrente da baixa disponibilidade de nutrientes em função da elevação do pH e da inibição competitiva de alguns cátions causada pelo possível excesso de $\mathrm{Ca}^{+2}$ e $\mathrm{Mg}^{+2}$ (Tabela 2). Deficiências de micronutrientes, como zinco, boro e manganês, podem ocorrer em situações de correção excessiva, causando redução do rendimento nestas situações (Volkweiss et al., 1992).

Na caracterização em solução nutritiva, o comprimento radicular aos 20 dias (CF) apresentou interação entre as espécies avaliadas e os níveis de alumínio $(\mathrm{P}<0,0001)$. Na ausência de alumínio na solução nutritiva, a alfafa apresentou comprimento radicular de $16,2 \mathrm{~cm}$, cerca de 3 a 4 vezes superior ao das espécies diploides de Lotus avaliadas. Entre as espécies de Lotus avaliadas nesta solução, L. japonicus MG-20 apresentou comprimento radicular superior $(5,6 \mathrm{~cm})$ às demais, que não diferiram entre si e apresentaram média de $3,25 \mathrm{~cm}$ (Figura 2).

A presença de $50 \mu \mathrm{M}$ de alumínio reduziu drasticamente o crescimento radicular da alfafa (88\%), confirmando a sensibilidade dessa espécie ao alumínio tóxico. Nesta concentração de alumínio, todos os genótipos de Lotus avaliados mantiveram o comprimento radicular final semelhante ao tratamento sem alumínio. Destaca-se novamente a espécie modelo $L$. japonicus MG-20, que foi superiores a todas as demais espécies. As concentrações de 100 e $200 \mu \mathrm{M}$ de alumínio reduziram significativamente o comprimento de todas as espécies de Lotus em relação à concentração de $50 \mu \mathrm{M}$ de alumínio $(\mathrm{P}<0,0001)$, sendo que a espécie $L$. japonicus MG-20 continuou apresentando maior comprimento radicular final $(\mathrm{P}<0,0001)$. Já a alfafa, apresentou comprimento radicular final semelhante entre os níveis entre 50 e $200 \mu \mathrm{M}$ de alumínio, resultado de uma ampla redução do comprimento radicular final já no nível $50 \mu \mathrm{M}$.

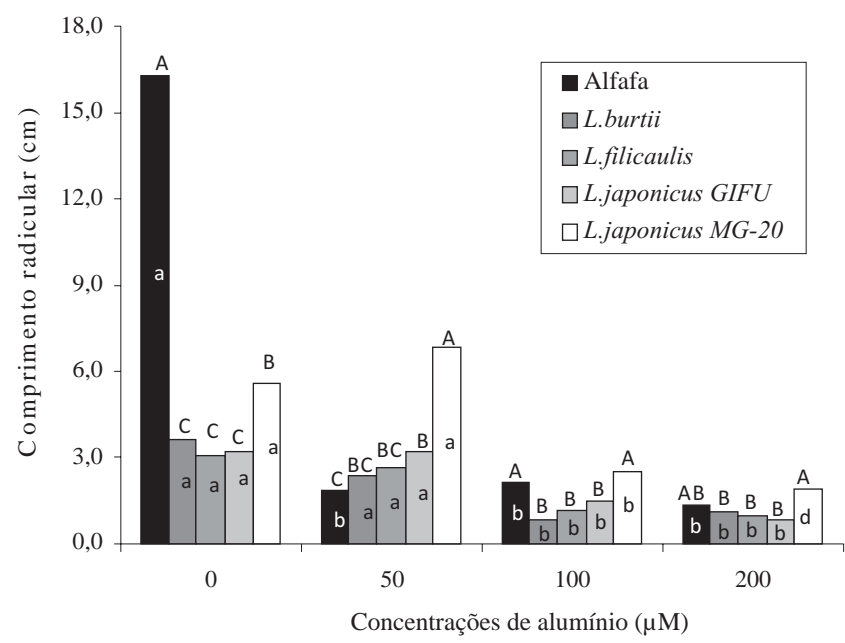

Letras minúsculas e maiúsculas indicam diferenças significativas pelo teste Tukey a 5\% de probabilidade entre os valores de saturação por Al de um mesmo germoplasma e entre os germoplasmas em determinado valor de saturação por $\mathrm{Al}$, respectivamente.

Figura 2 - Comprimento da raiz principal de quatro genótipos diploides de Lotus e alfafa crioula cultivadas durante 20 dias em solução nutritiva contendo diferentes níveis de alumínio.

Para o crescimento radicular também foi observada interação entre as espécies avaliadas e as concentrações de alumínio utilizadas $(\mathrm{P}<0001)$. Na ausência do metal, a alfafa apresentou crescimento radicular $(14,2 \mathrm{~cm})$, superior a todas as espécies de Lotus. Entre estas espécies, destacou-se a espécie modelo L. japonicus MG-20 ( $\mathrm{P}<0,001)$, com média de 4,18 cm, contra 2,2 cm das demais espécies (Figura 3).

A concentração de $50 \mu \mathrm{M}$ de alumínio foi suficiente para estagnar o crescimento radicular da alfafa e não afetou nenhuma das espécies de Lotus testadas. Comportamento diferenciado foi observado na espécie modelo $L$. japonicus MG-20, que apresentou melhor crescimento superior em relação à ausência do alumínio $(\mathrm{P}<0,001)$. Isso pode estar relacionado a um fenômeno denominado hormese, já descrito na literatura (Oller et al., 2004). Esse comportamento diz respeito a estímulos em baixas concentrações e inibição em concentrações mais elevadas de alumínio. Esse efeito foi recentemente também descrito através da análise de danos na estrutura do DNA de Allium cepa (Achary \& Panda, 2010), quando os autores descreveram um papel protetor observado em baixas concentrações de alumínio.

A concentração $100 \mu \mathrm{M}$ de alumínio afetou o crescimento radicular de todas as espécies de Lotus, com redução de mais de 70\%. Mesmo nessas condições, a espécie modelo L. japonicus MG-20 novamente se destacou dos demais, com crescimento $150 \%$ superior à espécie modelo L. japonicus GIFU, e mais de $300 \%$ superior as espécies L. filicaulis e L . burtii. O comportamento observado neste 


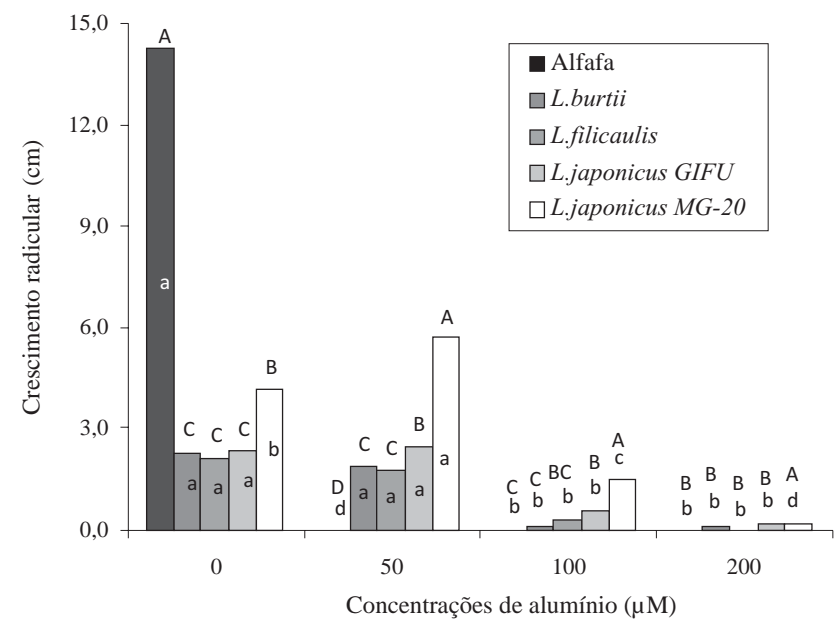

Letras minúsculas e maiúsculas indicam diferenças significativas pelo teste Tukey a 5\% de probabilidade entre os valores de saturação por Al de um mesmo germoplasma e entre os germoplasmas em determinado valor de saturação por $\mathrm{Al}$, respectivamente.

Figura 3 - Crescimento radicular de quatro germoplasmas diploides de Lotus e alfafa crioula cultivadas em solução nutritiva contendo diferentes concentrações de alumínio.

tratamento indica que $50 \mu \mathrm{M}$ de alumínio seria a concentração limite para a manutenção do crescimento radicular nas espécies diploides. Comparando aos resultados obtidos em germoplasmas de cornichão (Santos, 2009), observa-se que esses germoplasmas apresentam maior tolerância ao alumínio e suportam níveis de até $100 \mu \mathrm{M}$ desse metal em solução.

O nível $200 \mu \mathrm{M}$ de alumínio inibiu quase totalmente o crescimento radicular de todas as espécies, demonstrando ter sido extremamente tóxico. Pela análise do crescimento radicular relativo, observaram-se resultados contraditórios aqueles observados para crescimento radicular (Figura 4).

A padronização do crescimento na ausência de alumínio realizada pela análise do crescimento radicular relativo permitiu uma equiparação percentual equilibrada, mesmo em espécies com característica de crescimento distintas. No caso deste experimento, pôde-se equiparar o crescimento da alfafa (espécie mais precoce no desenvolvimento radicular) com as espécies diploides de Lotus. Desta forma, ao se avaliar a concentração $50 \mu \mathrm{M}$ de alumínio, observou-se a formação de quatro grupos, distintos entre si $(\mathrm{P}<0,01)$. $\mathrm{O}$ maior crescimento radicular relativo foi observado na espécie L. japonicus MG-20, seguida de L. japonicus GIFU; o terceiro grupo foi formado por L. filicaulis e L.burtii e, por ultimo, a alfafa, com crescimento radicular relativo zero, já na concentração de $50 \mu \mathrm{M}$ de alumínio. Assim como observado no crescimento relativo, a concentração $100 \mu \mathrm{M}$ de alumínio limitou drasticamente o crescimento radicular

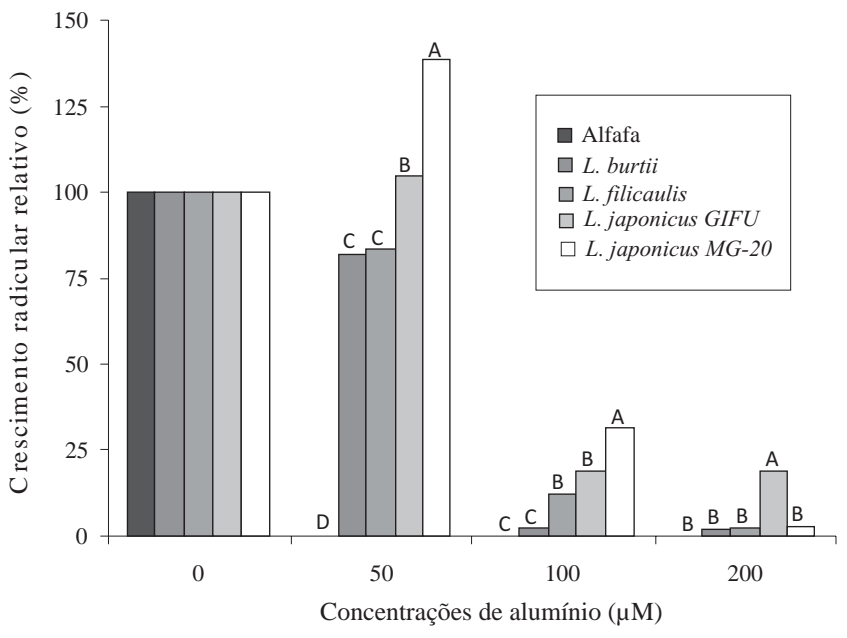

Letras minúsculas diferem os genótipos dentro de cada dose pelo teste Tukey a $5 \%$ de probabilidade.

Figura 4 - Crescimento radicular relativo em quatro germoplasmas diploides de Lotus e em alfafa cultivadas em solução nutritiva por um período de 30 dias.

relativo em todos os genótipos avaliados, com destaque positivo para a espécie $L$. japonicus MG-20.

Na solução com $200 \mu \mathrm{M}$ de alumínio, novamente observaram-se diferentes comportamentos para o crescimento radicular com o crescimento radicular relativo. Neste último, a espécie $L$. japonicus GIFU se destacou das demais neste nível de alumínio. Por se tratar de uma equação que inclui uma proporção entre o crescimento radicular em diferentes níveis, espécies com crescimento radicular menor na ausência de alumínio apresentarão crescimento radicular relativo superior em níveis mais drásticos de alumínio, mesmo que os valores de crescimento radicular nesses níveis sejam semelhantes, como foi o caso do crescimento radicular relativo das espécies modelo L japonicus MG-20 e GIFU na concentração de $200 \mu \mathrm{M}$ de alumínio.

Das quatro soluções utilizados na caracterização das espécies diploides, o que continha $50 \mu \mathrm{M}$ de alumínio apresentou maior variabilidade entre os germoplasmas. Por este motivo, a comparação das linhas endogâmicas recombinantes foi realizada nesta concentração de alumínio.

Das 63 linhas endogâmicas recombinantes provenientes de $L$. japonicus, dez apresentaram comprimento radicular superior e onze inferior $(\mathrm{P}<0,10)$ em relação à testemunha (L. japonicus GIFU). Como destaque das tolerantes podem-se citar os genótipos KOREA, CHURUI, MGs35, 46, 79, 82, 100, 109, 115 e 117 e, como sensíveis, os genótipos MGs12, 29, 39, 49, 62, 71d, 74, 75, 101, 111 e 123. Ampla variabilidade de resposta pôde ser observada entre as linhas endogâmicas recombinantes. Analisando os extremos, 
observou-se um comprimento radicular mais de $40 \%$ superior nas linhas endogâmicas recombinantes KOREA e MGs 79, 82, 100, 115 e 117 e mais de 50\% inferior nas linhas endogâmicas recombinantes MG-39 e 123, em relação ao ecótipo GIFU.

Com relação às 87 linhas endogâmicas recombinantes provenientes do cruzamento entre $L$. japonicus GIFU × L. burtii, observaram-se nove genótipos tolerantes (GLB5, 8, 28,38, 61, 98, 99, 169 e 175) e vinte e três sensíveis em relação ao genótipo GIFU (GLB1, 4, 13, 27, 35, 37, 43, 44, 52, 63, 64, 67, 69, 73, 74, 89, 95, 107, 108, 184, 188, 190 e 198). Novamente, uma ampla diversidade de resposta também foi encontrada neste conjunto de linhas endogâmicas recombinantes. As linhas GLB 5, 99 e 169 apresentaram-se mais de $50 \%$ superiores ao ecótipo GIFU, enquanto que as linhas endogâmicas recombinantes GLB 4, 68 e 95 apresentaram mais de $50 \%$ de redução em relação a este mesmo ecótipo.

Já no teste dos 30 genótipos provenientes de L. japonicus $\times$ L . filicaulis, foram observados seis genótipos superiores (NS53, 61, 92, 95, 141 e 177) e cinco inferiores (NS16,33, 81, 116 e 173). Neste grupo de plantas, a variabilidade encontrada foi superior à dos demais. A linha NS 92 apresentou comprimento radicular 166\% superior ao do ecótipo GIFU. Adicionalmente, as linhas endogâmicas recombinantes NS 141 e 177 foram cerca de 50\% superior a este ecótipo. Por outro lado, a LER NS 16 apresentou apenas $76 \%$ de redução do comprimento radicular, enquanto as linhas NS 33 e 116 apresentaram redução de cerca de 40\% em relação ao ecótipo GIFU.

Alta variabilidade para a tolerância ao alumínio vem sendo citada por diversos autores (Delhaize et al., 1995; Ma et al., 2001; Ermolayev et al., 2003) e isso indica que alguns genótipos ou espécies de plantas desenvolveram mecanismos de sobrevivência a este estresse. Essas estratégias de tolerância podem envolver exclusão do alumínio radicular e/ou neutralização do alumínio tóxico dentro da célula (Samac \& Tesfaye, 2003) e podem estar se expressando de maneiras distintas nas diversas linhas endogâmicas recombinantes avaliadas.

\section{Conclusões}

Níveis entre 20 e 35\% de saturação por alumínio no solo e de $50 \mu \mathrm{M}$ de alumínio em solução de cultivo são adequados para a seleção de plantas visando tolerância à toxidez por alumínio. O crescimento radicular relativo é a variável que melhor distingue os genótipos em solução nutritiva. Os ecótipos MG-20 e GIFU apresentam maior tolerância ao alumínio, enquanto $L$. filicaullis é a espécie de menor produção. Há grande variabilidade nas linhas endogâmicas recombinantes avaliadas, e indivíduos contrastantes podem ser utilizados em análises moleculares com o objetivo de identificar regiões genômicas responsáveis pela tolerância ou sensibilidade ao alumínio.

\section{Referências}

ACHARY, V.M.M.; PANDA, B.B. Aluminium-induced DNA damage and adaptive response to genotoxic stress in plant cells are mediated through reactive oxygen intermediates. Mutagenesis, v.25, n.2, p.201-209, 2010

COMISSÃO DE QUÍMICA E FERTILIDADE DO SOLO - RS/SC Manual de adubação e calagem para os Estados do Rio Grande do Sul e de Santa Catarina. 10.ed. Porto Alegre, SBCS - Núcleo Regional Sul/UFRGS, 2004. 400p.

DELHAIZE, E.; RYAN, P.R. Aluminum toxicity and tolerance in plants. Plant Physiology, v.107, n.2, p.315-321, 1995.

ERMOLAYEV, V.; WESCHKE, W.; MANTEUFFEL, R. Comparison of Al-induced gene expression in sensitive and tolerant soybean cultivars. Journal of Experimental Botany, v.54, n.393, p.2745-2756, 2003.

FOY, C.D.; CHANEY, R.L.; WHITE, M.C. The phisiology of metal toxicity in plants. Annual Reviews Plant Physiology, v.29, n.1, p.511-566, 1978.

FOY, C.D.; DUNCAN, R.R.; WASKON, R.M. et al. Tolerance of sorghum genotypes to an acid, aluminum toxic tatum subsoil. Journal of Plant Nutrition, v.161, p.97-127, 1996.

GUETA-DAHAN, Y.; YANIV, Z.; ZILINSKAS, B.A. et al. Salt and oxidative stress: similar and specific responses and their relation to salt tolerance in Citrus. Planta, v.203, n.4, p.460-469, 1997.

MA, J.F.; RYAN, P.R.; DELHAIZE, E. Aluminium tolerance in plants and the complexing role of organic acids. Trends in Plant Science, v.6, p.273-278, 2001.

MENOSSO, O.G.; COSTA, J.A.; ANGHINONI, I. et al. Tolerância de genótipos de soja ao Al em solução. Pesquisa Agropecuária Brasileira, v.35, n.11, p.2157-2166, 2000.

OLLER, A.; BATES, H. Metals and hormesis. Journal of Environmental Monitoring, v.6, p.14-19, 2004.

RAO, I.M.; ZEIGER, R.S.; VERA, R. et al. Selection and breeding for acid-soil tolerance in crops. Bioscience, v.43, n.7, p.454-465 1993.

SAMAC, D.A.; TESFAYE, M. Plant improvement for tolerance to aluminum in acid soils - a review. Plant Cell, Tissue and Organ Culture, v.75, p.189-207, 2003.

SANTOS, A.M. Melhoramento genético de Lotus corniculatus visando tolerância à toxidez por alumínio. 2009. $181 \mathrm{f}$. Tese (Doutorado em Zootecnia) - Faculdade de Agronomia, Universidade Federal do Rio Grande do Sul, Porto Alegre.

VOLKWEISS, S.J.; TEDESCO, M.J.; GIANELLO, C. et al. A calagem dos solos ácidos: prática e benefícios. 2.ed. Porto Alegre: Faculdade de Agronomia/UFRGS, 1992. 16p.

WENZL. P.; ARANGO, A.; CHAVES, A.C. et al. A greenhouse method to screen brachiariagrass genotypes for aluminum resistance and root vigor. Crop Science, v.46, p.968-973, 2006.

WHEELER, D.M.; DODD, M.B. Effect of aluminium on yield and plant chemical concentrations of some temperate legumes. Plant and Soil, v.173, n.1, p.133-145, 1995. 